\title{
APROXIMAÇÕES ENTRE ANTROPOLOGIA E DIREITO: OS LAUDOS ANTROPOLÓGICOS NA AFIRMAÇÃO E GARANTIA DAS TERRITORIALIDADES QUILOMBOLAS
}

\author{
João Vitor Martins Lemes ${ }^{1}$
}

\begin{abstract}
RESUMO: As territorialidades quilombolas são garantias muito recentes considerando os históricos das questões agrária e quilombola brasileiras. Todavia, apesar da clara garantia das territorialidades tradicionais no ordenamento jurídico pós-88, no plano material, as territorialidades não são efetivamente garantidas, em razão de dificuldades do Estado e, especificamente, do direito, em diversas ordens. Levando em consideração que as contribuições do saber antropológico apontam novos caminhos no sentido de superação dos obstáculos impostos à garantia dessas territorialidades, o presente artigo propõe-se refletir de que forma os laudos periciais antropológicos contribuem para a garantia das territorialidades quilombolas.
\end{abstract}

PALAVRAS-CHAVE: Comunidades quilombolas; Laudos Periciais Antropológicos; Territorialidades.

\section{APPROACHES BETWEEN ANTHROPOLOGY AND LAW: THE ANTHROPOLOGICAL REPORTS IN THE AFFIRMATION AND GUARANTEE OF QUILOMBOLAS TERRITORIALITIES}

\begin{abstract}
The quilombolas territorialities are very recent guarantees considering the history of Brazilian agrarian and quilombola issues. However, in spite of the clear guarantee of traditional territorialities in the post- 88 legal order, in the material plane, territorialities are not effectively guaranteed, due to difficulties of the State and, specifically, of the law, in several orders. Considering that the contributions of anthropological knowledge point to new ways of overcoming the obstacles imposed to the guarantee of these territorialities, the present article proposes to reflect in what way the anthropological expert reports contribute to the guarantee of quilombolas territorialities.
\end{abstract}

KEYWORDS: Anthropological Expert Reports; Quilombola communities; Territorialities

\section{INTRODUÇÃO}

O presente trabalho é um ponto de partida para as reflexões que o projeto de tese homônimo em desenvolvimento no Programa de Pós-Graduação em Antropologia Social da Universidade Federal de Goiás e objetiva compreender, a partir do estudo das categorias utilizadas pela antropologia e, muitas vezes ignoradas pelo direito, a importância dos laudos periciais antropológicos na afirmação das territorialidades quilombolas, com base do estudo

\footnotetext{
1 Doutorando em Antropologia Social e Mestre em Direito Agrário pela Universidade Federal de Goiás. Professor do curso de Direito da Universidade Federal de Goiás, Regional Goiás, Unidade Acadêmica Especial de Ciências Sociais Aplicadas.
} 
dos processos judiciais e administrativos em que sejam partes as comunidades quilombolas, de forma a estabelecer um panorama acerca da contribuição dos laudos na garantia dos territórios desses sujeitos.

As territorialidades quilombolas são uma garantia muito recente considerando o histórico da questão agrária e quilombola brasileiras. A estes sujeitos foi negada/inibida a possibilidade de acesso à terra no processo de formação político territorial brasileiro e, somente quase na segunda metade do século XX, reconhecendo a necessidade de uma postura recogniscitiva e redistributiva ${ }^{2}$ por parte do Estado em virtude da violação de direitos dessas comunidades, essas territorialidades foram asseguradas pelo direito nacional, no art. $68^{3}$ dos dispositivos constitucionais transitórios da Constituição democrática de 1988.

Indubitavelmente, a garantia das territorialidades no âmbito legal foi um avanço importante na luta pelo reconhecimento dos direitos dos povos tradicionais. Todavia, no plano material, as territorialidades não são efetivamente garantidas, em razão de dificuldades do Estado e, especificamente, do direito, em diversas ordens: os desafios vão desde a falta da compreensão de que essas comunidades possuem identidades específicas até o questionamento dos instrumentos normativos que garantem o acesso aos territórios, a partir da postura redistributiva do Estado. Tais dificuldades se materializam em uma infinidade de comunidades que desconhecem seus direitos e, se conhecem, tem muita dificuldade em acessar os seus territórios.

Dentre todos os desafios, o principal é a assimilação da existência de identidades coletivas e o reconhecimento das mesmas, considerando "[...] que no seio da comunidade nacional, há grupos portadores de identidades específicas e que cabe ao Estado assegurar-lhes o controle de suas próprias instituições e formas de vida e seu desenvolvimento econômico e manter e fortalecer suas entidades, línguas e religiões" (PEREIRA, 2009).

Pois bem. Levando em consideração os desafios para a afirmação das territorialidades quilombolas e partindo do pressuposto que as contribuições do saber antropológico, sobretudo com a discussão das categorias identidade e territorialidade, apontam novos caminhos no sentido de superação dos obstáculos impostos à garantia dessas territorialidades, o presente

\footnotetext{
${ }^{2}$ Segundo Nancy Fraser, como as desigualdades são construídas sob uma base material, é preciso pensar economicamente em formas de superá-la, considerando, então, a diferença entre lutas por redistribuição e lutas por reconhecimento e que "[...] somente olhando para as abordagens integrativas que unem redistribuição e reconhecimento podemos encontrar as exigências da justiça como um todo" (FRASER, 2008).

${ }^{3} \mathrm{O}$ art. 68 dos dispositivos constitucionais transitórios da Constituição democrática de 1988 reconheceu a propriedade das terras as quais os quilombolas estivessem ocupando, estabelecendo que o Estado deveria tomar as medidas necessárias para a emissão dos respectivos títulos de propriedade.
} 
artigo propõe-se a iniciar as reflexões teóricas acerca da maneira que os laudos periciais antropológicos contribuem para a garantia das territorialidades quilombolas.

Como hipótese à problemática apresentada, compreende-se que, apesar da evolução apresentada pelo Estado na efetivação das territorialidades quilombolas através da criação e normas específicas, o direito por si só não consegue garantir o acesso aos territórios quilombolas, já que seus conceitos e instrumentos foram forjados na perspectiva civilindividualista do Estado moderno e legitimado por um discurso competente eurocêntrico.

Dessa forma, necessita o direito na maioria das vezes de recorrer à antropologia e às categorias proporcionadas por esta, como a identidade, a etnicidade, a territorialidade, por meio das discussões nos laudos periciais antropológicos. Esses laudos representam, assim, um relevante instrumento para a garantia das territorialidades quilombolas, capaz de superar os desafios materializados às comunidades no acesso aos seus territórios. A presença dos laudos periciais antropológicos nos processos administrativos e judiciais e as discussões que estes possibilitam são um diferencial no resultado da garantia ou negação dessas territorialidades.

Nesse sentido, objetivando estabelecer um caráter linear e coeso às reflexões aqui propostas o texto está estruturado em três partes. A primeira, intitulada "Identidade, cultura, etnicidade e territorialidades", propõe-se a discutir esses conceitos e refletir sobre a maneira que incidem na realidade das comunidades tradicionais, em especial as comunidades quilombolas.

A segunda parte, Territorialidades quilombolas e o ordem do direito, apresenta um panorama da situação dos direitos territoriais das comunidades quilombolas e, a partir da reflexão sobre a postura do Estado frente às demandas identitárias dessas comunidades, aponta alguns problemas da ordem do direito ao discutir direitos e sujeitos coletivos que fogem à racionalidade do direito moderno, com sujeitos e direitos individualizados e para destinatários específicos.

Por fim, a última parte, chamada "A título de conclusão ou considerações iniciais acerca da interface antropologia-direito", apresenta alguns apontamentos iniciais sobre pontos de aproximação e distanciamento entre o campo da antropologia e do direito, sobremaneira a partir do papel dos laudos periciais na afirmação e garantia das territorialidades tradicionais, perceptíveis desde o estudo das categorias e conceitos apresentados na primeira parte e a sua aplicação/não aplicação na ordem do direito posto, conforme o panorama apresentado na segunda parte. 


\section{I - IDENTIDADE, CULTURA, ETNICIDADE E TERRITORIALIDADES}

A questão territorial das comunidades quilombolas é um tema de grande complexidade considerando que os seus modos de vida fogem da racionalidade moderna, não possuindo o Estado e o direito instrumentos capazes de alcançar todas as suas dimensões. Por se tratarem de grupos essencialmente ligados ao espaço agrário, a garantia de suas territorialidades, para além do seu sustento físico, é a maneira de preservar as tradições, memórias e cultura desses grupos formadores da sociedade brasileira. Essas comunidades, dessa maneira, são caracterizadas pela sua condição de coletividade e definidas pelo compartilhamento de um território e uma identidade.

A identidade é o sentimento de pertença que um indivíduo tem com seu grupo, permitindo que o indivíduo que se sinta integrante a um grupo possa afirmar-se com tal, preservando a sua cultura, seus valores e sua visão de mundo. É considerada um direito fundamental, dado que é uma garantia a qual, mesmo não estando expressamente na Constituição Federal, decorre diretamente dos princípios por ela adotados, como o Princípio da Dignidade da Pessoa. Pode-se perceber, ainda, referências à proteção desse direito em alguns dispositivos da carta constitucional: já no Preâmbulo, o constituinte estabelece que uma das finalidades da República Federativa do Brasil é a criação de uma “[...] sociedade fraterna, pluralista e sem preconceitos" (BRASIL, 1988).

A título de exemplo dessa postura assumida pelo Estado brasileiro, têm-se os artigos 215 e $216^{4}$ da Constituição Federal, que inserem no rol dos direitos culturais a valorização do direito à identidade, reconhecendo-a a esses sujeitos e, consequentemente, demonstrando a necessidade de proteção/preservação dos espaços em que eles vivem/se constituem. Além disso, lembre-se da garantia dos direitos territoriais, tanto dos indígenas quanto dos quilombolas, no Ato das Disposições Constitucionais Transitórias (ADCT) .

Essa noção de identidade que embasa o reconhecimento de diversas grupos no seio da sociedade nacional por parte do constitucionalismo democrático vai ser consolidada a

\footnotetext{
${ }^{4}$ Art. 215. [...]

$\S 3^{\circ}$. A lei estabelecerá o Plano Nacional de Cultura, de duração plurianual, visando ao desenvolvimento cultural do País e à integração das ações do poder público que conduzem à:

[...]

V - Valorização da diversidade étnica e regional.

Art. 216. Constituem patrimônio cultural brasileiro os bens de natureza material e imaterial, tomados individualmente ou em conjunto, portadores de referência à identidade, à ação, à memória dos diferentes grupos formadores da sociedade brasileira. (BRASIL, 1988).
} 
partir da reflexão de Weber sobre as relações étnicas na qual, a partir do estranhamento às diferenças, a desconstrução do conceito de raça e a afirmação do conceito de etnia, ultrapassando os elementos genéticos e biológicos vão diferenciar múltiplos grupos, cada qual com suas características e singularidades, num sentido de grupo étnico:

[...] aqueles grupos humanos que, em virtude de semelhanças no habitus externo ou nos costumes, ou em ambos, ou em virtude de lembranças de colonização e migração, nutrem uma crença subjetiva na procedência comum, de tal modo que esta se torna importante para a propagação de relações comunitárias, sendo indiferente se existe ou não uma comunidade de sangue efetiva (WEBER, 2000, p. 270).

Fredrik Barth, a partir da ruptura proposta por Weber ao assinalar a noção de identidade para além da noção racial no campo da biologia, avança na construção dessa noção identitária, definindo os grupos étnicos/ etnias a partir das permanências das diferenças nos aspectos não naturalizados entre grupos distintos. Nessa linha, a identidade, tanto para Barth quanto para Weber, é uma construção social que só faz sentido desde a existência do da figura do outro (BARTH, 2000).

A identidade, assim, é conceito contrativo, que se dá no espaço do encontro, da fronteira. Essa dinâmica apresentada por Barth é perfeitamente traduzida por Roberto Cardoso de Oliveira:

\begin{abstract}
Partindo de Barth, pudemos então elaborar a noção de identidade contrastiva, tomando-a como essência da identidade étnica: a saber, quando uma pessoa ou um grupo se afirmam como tais, o fazem como meio de diferenciação em relação a alguma outra pessoa ou grupo com que se defrontam: é uma identidade que surge por oposição, implicando a afirmação do nós diante do outros, jamais se afirmando isoladamente. Um indivíduo ou um grupo indígena afirma sua etnia contrastando-se com uma etnia de referência tenha ela um caráter tribal (por exemplo, Terêna, Tikuna, etc) ou nacional (por exemplo, brasileiro, paraguaio, etc). O certo é que um membro de um grupo indígena não invoca sua pertinência tribal a não ser quando posto em confronto com membros de outra etnia. Em isolamento, o grupo tribal não tem necessidade de qualquer designação específica (OLIVEIRA, 1976, p. 36).
\end{abstract}

No caso das comunidades tradicionais em geral e, em especial das comunidades quilombolas, essa identidade se manifesta, com maior força, por meio da relação com a terra, já que para eles, esta não é vista apenas na sua dimensão patrimonial.

O território constitui um dos mais importantes componentes da identidade destes grupos, já que é justamente na relação que as comunidades mantêm com a terra e a natureza que se constrói uma identidade: os modos de fazer, de viver e de criar destas comunidades se articulam, inteiramente, dentro destas terras, inclusive suas práticas culturais e religiosas. 
Nesse sentido, Milton Santos pondera que o território deve ser compreendido na dimensão do seu uso/utilização e não apenas tomando por base o espaço físico, de forma que, ao falar em território deve se entender que se faz referência ao espaço utilizado para a reprodução física e/ou cultural de determinado grupo: “[...] O território é o chão e mais a população, isto é, uma identidade, o fato e o sentimento de pertencer àquilo que nos pertence. O território é a base do trabalho, da residência, das trocas materiais e espirituais e da vida, sobre os quais influi"' (SANTOS, 2000, p. 96).

Em seu estudo "Por uma abordagem territorial", Marcos Aurélio Saquet acrescenta aos ensinamentos de Milton Santos que "a própria identidade é substantivada por relações desiguais e por diferenças o que, contraditoriamente, torna mais complexas e dificulta nossas atividades de pesquisa e leitura dos fenômenos e processos territoriais" (SAQUET, 2009).

E, nesse processo de afirmação identitária, um elemento que, segundo Duprat (2012), se apresenta como imperativo de uma sociedade democrática, é a auto atribuição. Esse conceito constitui-se na premissa que as comunidades tradicionais são as competentes para assegurar a sua condição, partindo da visão do próprio grupo, tomando em conta suas vivências, seus costumes e suas tradições. A auto atribuição pressupõe a consciência do próprio grupo, levando em consideração suas características, quais sejam: a sua forma de organização, a sua ancestralidade, os seus elementos linguísticos, a sua religião, sua maneira de relacionar com a terra.

Sobre esse elemento formador do conceito de identidade, Alfredo Wagner propõe que o ponto central de debate perpassa pela forma com que os próprios sujeitos se definem dentro de uma coletividade, sendo essa atitude a expressão maior da afirmação da identidade coletiva de grupo: "o ponto de partida da análise crítica é a indagação de como os próprios agentes sociais se definem e representam suas relações e práticas face dos grupos sociais com que interagem" (ALMEIDA, 2002). Destacando a essencialidade da auto atribuição enquanto afirmação da identidade étnica, o autor acrescenta, ainda, que os procedimentos de definição que interessam "são aqueles construídos pelos próprios sujeitos a partir dos próprios conflitos, e não necessariamente aqueles que são produto de classificações externas, muitas vezes estigmatizantes" (ALMEIDA, 2002). 
Na mesma linha, complementa Daniel Sarmento, quando da elaboração do parecer do Ministério Público Federal no âmbito da ADI $3.239^{5}$ que a auto definição é uma categoria importante "na medida em que parte da correta premissa de que, na definição da identidade étnica, é essencial levar em conta a percepção dos próprios sujeitos que estão sendo identificados, sob pena de se chancelarem leituras etnocêntricas ou essencialistas dos observadores externos" (SARMENTO, 2008). O procurador conclui com a reflexão de que "na definição da identidade, não há como ignorar a visão que o próprio sujeito de direito tem de si, sob pena de se perpetrarem sérias arbitrariedades e violências, concretas ou simbólicas" (SARMENTO, 2008).

Sobre a territorialidade, enquanto modo dos povos e comunidades tradicionais se relacionarem com a terra é importante ressaltar que ela ocorre porque por meio do território é que se faz possível sua reprodução física e cultural, e a manutenção das suas características específicas. A reprodução física se dá no sentido de prover um meio de sustento aos membros do grupo, relacionada com a produção de alimentos para a subsistência a partir das práticas tradicionais. Por sua vez, a reprodução cultural ocorre na perspectiva de que a terra é fundamental na identificação do grupo étnico, pois este é retrato da maneira de como se relaciona com a terra, fazendo dela um lugar de manifestação e manutenção dos costumes e da sua forma de organização.

Nesse sentido, confirmando o caráter singular que possui a relação das comunidades tradicionais com a terra, Sundfeld defende que "[...] a territorialidade é um fator fundamental na identificação dos grupos tradicionais" (SUNDFELD, 2002). Destaca, ainda, que o aspecto territorial "[...] desvenda a maneira como cada grupo molda o espaço em que vive, e que se difere das formas tradicionais de apropriação dos recursos da natureza" (SUNDFELD, 2002).

Pois bem. A ordem constitucional inaugurada em 1988, estabelece, no plano legal, uma política de reparação que tem na sua essência o objetivo de, por meio do reconhecimento das identidades das comunidades quilombolas, propiciar o respeito à diferença. É importante destacar que a ideia de reparação por parte do Estado inserida no artigo 68 do ADCT não comporta interpretação apenas no sentido de compensação pelas

\footnotetext{
${ }^{5}$ A ADI $n^{\circ}$. 3.239/2004-DF é uma Ação Direta de Inconstitucionalidade paradigmática do ponto de vista de garantia dos direitos coletivos e da concretização de práticas que consagrem a tão festejada diversidade brasileira, posto que discute os critérios de acesso a terra por parte das comunidades quilombolas, instrumentalizado por meio do Decreto 4.887/2003.
} 
violações sofridas no passado (ideia da indenização), mas deve ser encarada numa perspectiva prospectiva, vislumbrando a sociedade a ser construída, multicultural e pluriétnica (PEREIRA, 2012).

Em outras palavras, essa feição estatal, sobretudo após a promulgação da Constituição de 1988, procura garantir a todas as pessoas o exercício da cidadania, independente das desigualdades formais/materiais existentes, por meio do reconhecimento das mais diversas identidades existentes na sociedade brasileira.

No entanto, para a efetiva promoção de uma sociedade fundada na igualdade e na justiça social são necessárias ações no campo do reconhecimento dessas múltiplas identidades.

O debate em torno do conceito de reconhecimento remonta ao pensamento de Hegel $^{6}$, tendo este sido atualizado e reintroduzido no campo filosófico e das ciências sociais por Paul Ricoeur, Charles Taylor e Axel Honneth, no sentido de que reconhecer não significa simplesmente identificar uma pessoa enquanto sujeito, mas, para além disso, atribuir um valor positivo àquele, conforme a ideia de respeito.

Nessa linha, Paul Ricoeur agrega ao debate do termo reconhecimento a necessidade de pensar esse conceito por meio de um olhar amplo, “[...] pois semanticamente pode significar desde a simples identificação até gratidão" (RICOEUR, 2006). A falta do reconhecimento ou este de maneira errônea pode causar danos à pessoa a depender da imagem atribuída a ela. Assim, o reconhecimento não deve ser considerado cortesia, mas uma necessidade humana a ser respeitada e provida.

A obra de Honneth é a principal contribuição acerca da significação de reconhecimento. Ele coloca, a partir do diálogo com a obra de Hegel, que é a luta pelo reconhecimento que constitui a gramática e a dinâmica dos conflitos sociais, identificando a existência de formas de reconhecimento: o amor, o direito e a solidariedade. Enquanto a esfera do amor permite ao indivíduo uma confiança em si mesmo, no campo jurídico, a pessoa individual é reconhecida como autônoma e moralmente imputável, desenvolvendo uma relação de auto-respeito e no espaço da solidariedade, é reconhecida como digna de estima social. Dessas três instâncias de reconhecimento, afirma Honneth que surgem "[...] três maneiras de desrespeito: a violação, a privação de direitos e a degradação, respectivamente"

\footnotetext{
${ }^{6} \mathrm{O}$ conceito de reconhecimento ganha status filosófico com a passagem sobre a Dialética do Senhor e do Escravo na obra Fenomenologia do Espírito, de Hegel.
} 
(HONNETH, 2009). E é na resistência a essas formas de não-reconhecimento que se desencadeiam os conflitos sociais.

No entanto, posto que as desigualdades são construídas sob uma base material, é preciso pensar economicamente em formas de superá-las, sendo a categoria reconhecimento apenas um dos aspectos a serem levados em conta.

Quem insere essa questão no debate é Nancy Fraser, filósofa política norte-americana que estabelece suas reflexões a partir da diferença entre lutas por redistribuição e lutas por reconhecimento. As primeiras são as motivadas pela desigualdade de classe social e as últimas pela subordinação de status. Fraser considera que a luta por reconhecimento é uma resposta genuinamente emancipatória para algumas questões de injustiça social, mas não para todas, e então propõe uma concepção de justiça que integre essas duas dimensões, enquanto para Honneth o conceito de reconhecimento já seja capaz de acomodar as demandas por redistribuição econômica.

Sobre as significações de redistribuição e reconhecimento, Fraser ensina que, atualmente, os processos de justiça social compreendem duas modalidades: "[...] as demandas redistributivas que buscam uma distribuição mais justa de recursos e bens" (FRASER, 2008, p. 167) e aquelas que visam "[...] justiça social, demandas que tem sido chamadas de "política do reconhecimento" (FRASER, 2008, p. 168). Nesse segundo tipo, Fraser acrescenta ainda que o objetivo desta "[...] é contribuir para um mundo amigo da diferença, onde a assimilação à maioria ou às normas culturais dominantes não é mais o preço do igual respeito" (FRASER, 2008, p. 167).

Depreende-se daí que "[...] somente olhando para as abordagens integrativas que unem redistribuição e reconhecimento podemos encontrar as exigências da justiça como um todo" (FRASER, 2008, p. 189).

Assim, no caso das comunidades tradicionais, não basta reconhecer sua identidade, mas é necessário pensar nas formas para que seja possível distribuir recursos que contemplem a ideia de justiça na sua completude.

\section{II - TERRITORIALIDADES QUILOMBOLAS E A ORDEM DO DIREITO}


A expressão da resistência dos negros à exploração da sua mão-de-obra no regime de exploração da terra no Brasil consistiu na organização dos quilombos ${ }^{7}$, hoje presentes por meio do reconhecimento da existência de comunidades quilombolas, sujeitos desse trabalho, em todas as regiões do Brasil. Sobre esses espaços, Ariovaldo Umbelino de Oliveira destaca que os quilombos eram "[...] lugares de resistência negra, um sistema comunitário de vida na floresta para onde iam os negros que conseguiam fugir da escravidão. Às vezes eram cinco, seis casas apenas. Outras vezes chegavam a formar verdadeiras cidades" (OLIVEIRA, 1994, p. 20).

A abolição, no fim do século XIX, não foi o fim dos problemas dos negros: ao passo que garantiu a liberdade, criou um grande problema social, pois não foi acompanhada da inserção dos escravos recém-libertos à sociedade: muitos deles - a grande maioria - não conseguiam empregos e sofriam preconceito e discriminação racial, passando a viver em habitações de péssimas condições e a sobreviver de trabalhos informais e temporários. Nessa linha, Araújo conclui que “[...] o término da escravidão não significou o fim dos conflitos, já que as injustiças sociais ainda permaneciam" (ARAÚJO, 1998, p. 187).

Esse processo de exclusão dos ex-escravos no fim do século XIX e início do século XX acabou acentuando, ainda mais, a marginalização e a exclusão desses grupos, além de fortalecer a dependência desses em relação aos senhores das terras e do capital.

A partir de 1988, com a promulgação da constituição cidadã, esse cenário tomou contornos diferentes, vez que os movimentos sociais ligados à questão quilombola conquistam o reconhecimento da identidade quilombola por meio dos direitos culturais, além do artigo nas disposições constitucionais transitórias que garante o acesso à terra aos quilombolas devendo o Estado instrumentalizar esse direito.

De lá para cá, a Fundação Cultural Palmares certificou $2.607^{8}$ comunidades como quilombolas espalhadas por todo o país, o INCRA, em parceria com os Institutos de Terras dos estados, certificou e expediu o título de propriedade coletiva para 217 comunidades ${ }^{9}$,

\footnotetext{
${ }^{7}$ Destaca-se, aqui, o Quilombo dos Palmares como grande expressão da resistência dos escravos durante o período colonial. Reunidos na Serra da Barriga, na então Capitania de Pernambuco, hoje estado de Alagoas, e liderado por Zumbi dos Palmares, esse espaço resistiu por mais de um século, se tornando um mito moderno de busca por liberdade numa época de escravidão.

8 Dados do site da Fundação Cultural Palmares e atualizados até 10/09/2015. Disponível em: <http://www.palmares.gov.br/?page_id=37551/>. Acesso em 14.out.2015.

9 Dados do site do Instituto Nacional de Colonização e Reforma Agrária. Disponível em: <http://www.incra.gov.br/quilombola>. Acesso em 14.out.2015.
} 
enquanto existem outros 1.290 processos $^{10}$ abertos de regularização fundiária junto ao INCRA, demonstrando um total descompasso entre o número de comunidades quilombolas e a quantidade delas que tem suas territorialidades asseguradas.

Esse descompasso revela a dificuldade do Estado de, por meio dos instrumentos puramente jurídicos, em garantir as territorialidades dessas comunidades. Nessa linha, em estudo recente sobre a postura do Estado, especificamente do poder judiciário nas ações que discutiam territorialidades quilombolas (LEMES, 2014), concluiu-se que na esmagadora maioria dos processos analisados, não há debate sobre o reconhecimento das identidades e coletividades que formam os territórios brasileiros e que necessitam de interpretações jurídicas coerentes aos seus contextos. Essas particularidades são invisibilizadas e marginalizadas, predominando, nas ações, o debate sobre os fundamentos e critérios do instituto de propriedade, encarado de forma absoluta.

Assim, no caso das comunidades quilombolas, é possível visualizar ações judiciais que ora garantem os direitos territoriais, ora negam, com as justificativas que referendam uma ou outra concepção de territorialidade quilombola.

É o que acontece no caso da ação judicial envolvendo a comunidade quilombola André Lopes, em São Paulo, na qual o juiz reconhece os direitos dos sujeitos coletivos, em decisão atenta às territorialidades específicas. Tal julgado se mostra sensível à importância da valorização das identidades quilombolas, adotando posicionamento favorável à constitucionalidade do Decreto 4.887/2003:

$[\ldots]$

O Quilombo André Lopes, isto é, a comunidade quilombola moradora do Bairro André Lopes, em Eldorado/SP, é uma das que permanecem no Vale do Ribeira.

São membros de famílias descendentes de escravos negros trazidos ao Vale do Ribeira para trabalhar na extração de ouro durante os séculos XVII e XVIII, que aguardam ansiosamente a titulação de suas terras, garantida no art. 68 do ADCT. Essas pessoas são descendentes daqueles que há trezentos e cinquenta (350) anos foram trazidos à força para o local e hoje vivem basicamente da cultura de arroz, feijão e milho. No Estado de São Paulo são contabilizadas 48 áreas quilombolas, mas ao que se sabe apenas cinco (5) delas receberam títulos de terra regularizando documentalmente aquilo que a Constituição assegura.

A burocracia governamental sofre pressão dos agronegócios para negar ou retardar a regularização fundiária dos quilombos; isso alia-se ao racismo declarado da sociedade brasileira que, paradoxalmente, embora miscigenada, discrimina os negros.

Desde o já distante ano de 1988, no plano federal, somente em 20 de novembro de 2003 - Dia Nacional da Consciência Negra - foi editado um decreto presidencial com regras mais adequadas e com ares democráticos (Decreto ${ }^{\circ} 4.887$ ) para

10 Dados do site do Instituto Nacional de Colonização e Reforma Agrária. Disponível em: <http://www.incra.gov.br/quilombola>. Acesso em 14.out.2015. 
regulamentar a titulação prevista no art. 68 do ADCT. Mas até hoje, esse útil instrumento não foi aplicado e enfrenta no Supremo Tribunal Federal a alegação de inconstitucionalidade proposta pelo Partido da Frente Liberal (PFL) na ADIN n ${ }^{\circ}$ 3.239 desde julho de 2004. Um decreto que em tese viabilizaria a resolução do problema da titulação de áreas quilombolas, num prazo estimado entre 11 a 13 meses para duração de cada procedimento, não é implementado na prática.

$[\ldots]$

(TRF $3^{\circ}$ REGIÃO - Agravo de Instrumento $n^{\circ}$. 265.684/SP. Processo $n^{\circ}$. 2006.03.00.029172-9. Relator Desembargador Johnson Di Salvo, primeira turma. DJ de 28/07/2006).

A partir de outro ponto de vista, vemos a negação dos direitos territoriais dessas comunidades, como na decisão em sede de apelação cível junto ao TRF-2, onde o INCRA sai em defesa de comunidade quilombola no âmbito de ação de desapropriação contra particular:

$[\ldots]$ Estabelece o art. 68 do ADCT da CRFB/88:

"Art. 68. Aos remanescentes das comunidades dos quilombos que estejam ocupando suas terras é reconhecida a propriedade definitiva, devendo o Estado emitir-lhes os títulos respectivos."

Editou-se, então, para a concreção da disposição constitucional em comento, o Decreto $\mathrm{n}^{\mathrm{o}} 4887 / 2003$, o qual traçou as diretrizes para o procedimento de identificação, reconhecimento, delimitação, demarcação e titulação das terras ocupadas por remanescentes das denominadas comunidades quilombolas.

Da detida análise dos autos, todavia, tem-se que o fundamento da Sentença de improcedência a quo foi a inconstitucionalidade do mencionado Decreto.

De fato, referido ato normativo foi objeto de questionamento no Supremo Tribunal Federal, por intermédio da ADI n³239/DF, havendo o Relator votado no sentido da sua inconstitucionalidade, tendo sido o julgamento, então, adiado em razão de pedido de vista.

Outrossim, conforme muito bem destacado pelo Exmo. Desembargador Federal Guilherme Calmon Nogueira da Gama, no julgamento do Agravo de Instrumento $\mathrm{n}^{\mathbf{o}}$ 201202010135167, o fato de que ainda não houve julgamento definitivo pelo STF não impede que o voto acima aludido seja tomado como paradigma, tendo em vista que os argumentos expendidos pelo Min. César Peluso são fortes e convincentes, podendo seu entendimento ser livremente adotado pelos demais magistrados.

E isto porque, compulsando as normas insertas no Decreto $n^{\circ} 4887 / 2003$, percebe-se que o mesmo realmente se distanciou do teor do art. 68 do ADCT. Senão vejamos: enquanto este último está direcionado "aos remanescentes das comunidades dos quilombos que estejam ocupando suas terras", ou seja, às pessoas físicas descendentes daqueles que integraram uma comunidade de quilombo e que estivessem, quando da promulgação da CRFB/88, ocupando aquelas terras, o Decreto em comento redefine o destinatário do dispositivo quando estabelece, em seu art. $2^{\circ}$, que "consideram-se remanescentes das comunidades dos quilombos, para fins deste Decreto, os grupos étnico-raciais", representados por "associações legalmente constituídas" (art. 17, parágrafo único), ampliando, assim, o alcance do dispositivo constitucional.

Registre-se, por oportuno, que o STJ já decidiu que "o instituto da desapropriação, por se tratar de exceção ao direito de propriedade, deve ser entendido de forma restritiva. Não cabe ao intérprete da norma autorizadora da desapropriação estender as hipóteses taxativamente previstas em Lei, sob pena de se desestabilizarem as relações dominiais, também protegidas pela Constituição Federal (art. $5^{\circ}$, inc. XXII) "RESP n ${ }^{\circ}$ 1.046.178GO, Relator Min. Mauro Campbell Marques.

Ademais, conforme muito bem observado pelo MM. Juízo a quo, o Decreto $\mathrm{n}^{\circ}$ $4887 / 2003$, em seu art. $2^{\circ}, \S 2^{\circ}$, cria uma verdadeira expansão da extensão territorial ao destacar que também "são terras ocupadas por remanescentes das comunidades 
dos quilombos as utilizadas para a garantia de sua reprodução física, social, econômica e cultural", o que, à toda evidência, conflita com a necessidade de interpretação restritiva acima afirmada.

[...]

(TRF 2a REGIÃO - Apelação Cível 611260/RJ. Processo nº 2012.51.09.0006835.

Relator: Desembargador Federal Reis Friede).

Nos casos de debate acerca da posse e propriedade, sobretudo quando os sujeitos são comunidades tradicionalmente vinculados ao espaço agrário, percebe-se que o Judiciário vem atuando entre duas concepções de propriedade, como afirma Boaventura de Sousa Santos: “[...] a concepção que tem na sua base o direito agrário, ligado ao trabalho; e as concepções individualistas do direito civil, com uma concepção de propriedade mais ligada ou à posse direta ou ao título. São duas concepções que estão, neste momento, em conflito”. (SANTOS, 2007).

Ademais, essas maneiras distintas de significação do instituto da propriedade, quando refletidas a partir da realidade dos quilombolas, apresentam novas complexidades, antes ocultadas pelo direito, tendo em vista que a noção de propriedade, tanto civil, quanto agrária, está assentada na perspectiva individual estabelecida pela modernidade. Do outro lado, a individualização do território quilombola não é possível, em razão que este está relacionado à própria existência coletiva dos sujeitos, constituindo o lugar que reúne as condições necessárias para a manutenção dos modos de fazer, viver e criar desse grupo.

Dessa forma, o território não é somente uma propriedade coletiva, no sentido de possuir o direito sobre o bem (objeto), mas configura uma pluralidade de sujeitos de direito, conforme afirma Marés: "há um grupo titular da propriedade coletiva formado por indivíduos, e o direito do grupo é o resultado da soma dos direitos de propriedade individual de seus integrantes” (MARÉS, 2010). Por sua vez, esses direitos coletivos representam “[...] o conjunto de direitos que um grupo humano tem sobre determinado objeto coletivo (coisas, relação, sistema ou conhecimento) sem poder ser chamado de direito de propriedade. [...]. O grupo é titular enquanto grupo e nenhum dos seus membros tem direito a parcela do todo". (MARÉS, 2010).

Nessa perspectiva, as relações desses sujeitos não se dão pelo contrato, mas se formam naturalmente, a partir de processos culturais, no reconhecimento e construção da identidade do grupo, cujo "fato é mais relevante que o direito" (MARÉS, 2010).

Além dessas questões levantas por Boaventura de Sousa Santos e Carlos Marés sobre a atuação do Judiciário é de se ressaltar o exposto por Luiz Edson Fachin, que considera que 
os juízes, em suas decisões referentes a conflitos rurais " [...] inspiram-se no absolutismo do direito de propriedade expresso num título para deferir proteção possessória, sem qualquer questionamento acerca das exigências constitucionais". (FACHIN, 2000)

Outrossim, Faria acrescenta que já existe um paradoxo na atuação do Poder Judiciário em relação aos conflitos territoriais, advindos da mobilização dos próprios sujeitos do espaço agrário (FARIA, 1992). Essa mobilização acrescenta um caráter político à postura do judiciário brasileiro frente às demandas de acesso a terra, já que as ações apreciadas são fruto da ação de movimentos organizados que buscam democratizar o espaço agrário (VIANA, 1997), sendo o judiciário, então, instância importante no sentido de democratizar esse espaço.

E, apesar da postura que a politização das questões que chegam ao judiciário atribuem aos julgadores, Faria assevera que “[...] grande parte dos profissionais do direito é formada num dogmatismo que não permite sequer o debate desses problemas. Atados à perspectiva interna ao direito, [...] desatentos quanto ao crescente uso político do direito, alguns setores da magistratura fazem vista grossa diante da nova realidade" (FARIA, 1989).

Percebe-se, então, a instrumentalização do Direito para manutenção de determinada ordem social e econômica que, segundo Boaventura de Sousa Santos, na estrutura do direito moderno utiliza-se, no momento da prestação da tutela jurisdicional, da "[...] positividade do direito como instrumento potencialmente inesgotável de dominação" (SANTOS, 2009).

Percebe-se, ainda, que o direito, por si só, não é suficiente para garantir as territorialidades quilombolas, sendo imprescindível a atuação direta da antropologia, já que esta é "[...] a ciência que deve compartilhar com o Direito o entendimento da relação dos povos, ou que nome se dê a estes grupos humanos, com os Estados Nacionais" (MARÉS, 2010).

\section{III - CONCLUSÃO ou CONSIDERAÇÕES INICIAIS SOBRE A INTERFACE ANTROPOLOGIA-DIREITO}

A antropologia é de fundamental importância para a compreensão da questão das territorialidades quilombolas, sobretudo a partir dos laudos periciais antropológicos, uma vez que, por si só o direito não consegue fornecer ao Estado elementos suficientes para garantir e tutelar as titularidades dos espaços que os quilombolas ocupam. 
É necessário, pois, um olhar a partir das categorias da antropologia para a efetivação das territorialidades tradicionais, uma vez que, inovam a percepção que o Estado tem desses novos sujeitos que não se enquadram nos parâmetros já estabelecidos e que reafirmam a lógica individualista e patrimonialista da sociedade de grande formato, sendo que, atualmente, a postura do Estado reafirma uma perspectiva civil-patrimonialista de garantia do direito de propriedade, entendida como um direito absoluto, desconsiderando o caráter coletivo dos sujeitos quilombolas (LEMES, 2014).

A partir da compreensão de que o saber jurídico por si só não seria capaz de dar ao Estado o aparato suficiente na efetivação das demandas territoriais quilombolas, é que se procura, no saber antropológico, a reposta aos problemas levantados desde o começo da trajetória de pesquisa sobre a temática, no sentido de que, com os estudos dos instrumentais antropológicos, especificamente os laudos periciais se vislumbrou o potencial da antropologia na afirmação das territorialidades quilombolas.

Esse campo do saber possibilita a discussão das categorias que o direito e, consequentemente, o Estado, não alcançam, como, por exemplo, a compreensão de quem é esse novo sujeito reconhecido que não se encaixam na caracterização de sujeito já existente, considerando que essas comunidades não podem ser simplesmente "integradas nos códigos de forma uniforme porque afinal, cada povo é único, não se admitindo generalizações que proporcionem uma "igualdade" entre eles" (MARÉS, 2010b).

A antropologia, assim, sobremaneira por meio dos laudos e perícias antropológicos que vão acabar por instruir os procedimentos administrativos e judiciais, tem possibilitado uma "[...] nova reconfiguração de saberes, propiciada por um campo de pesquisa que conjuga o envolvimento das comunidades pesquisadas, dos pesquisadores de várias áreas, militantes de movimentos sociais, dos profissionais de entidades e instituições públicas, entre outros" (CHAGAS, 2005).

$\mathrm{O}$ envolvimento com a realidade das comunidades e seus modos de fazer, viver e criar, numa perspectiva dialógica, é a primeira entre as contribuições do saber antropológico na afirmação das territorialidades quilombolas, uma vez que, a esses sujeitos, através dos laudos antropológicos, é oportunizado serem vistos a partir dos seus contextos específicos. Esses laudos consistem numa possibilidade de visualização no âmbito dos procedimentos administrativos e judiciais de conhecer "[...] as situações sociais pesquisadas e que várias vezes são invisibilizadas pelo senso comum" (OLIVEIRA, 2005) dos operadores do direito, 
que, na maioria das vezes, reproduzem a concepção de quilombos importadas do Conselho Ultramarino de $1740^{11}$, numa lógica conservadora e patrimonialista e, quando atualizadas, sempre priorizam as adjetivações "remanescentes" e "descendentes", remetendo a uma ideia de sobra, resíduos, ignorando e dificultando o reconhecimento das situações sociais do presente.

Nesse sentido, contribui a antropologia, também, pois é desde os laudos antropológicos que se alcança "[...] as autodenominações dos membros desses agrupamentos e atribui-se formas ressignificadas de interpretação, no presente, das lutas políticoorganizativas e jurídicas pela conquista e permanência na terra, teorizando-se a partir da realidade local" (OLIVEIRA, 2005).

Assim, a atuação conjunta da antropologia com o direito se torna uma realidade imperiosa, sopesando que, com o advento desses novos sujeitos, ao passo que ao direito é atribuída a tarefa de fazer com esses grupos tenham acesso às suas necessidades, só com o trabalho da antropologia - de interpretar, relacionar e fazer a interlocução dessas comunidades com o ordenamento já existentes - é que a tarefa do direito enquanto instrumental do Estado, se torna possível.

Ademais, é de se destacar que, na afirmação dos direitos dessas comunidades, a pertinência do saber antropológico é basilar, já que por meio dos laudos periciais antropológicos é que se legitimam os direitos desses novos sujeitos, a partir da inserção de subsídios para que decisões jurídicas sobre as vidas de grupos humanos respeitem ao máximo suas dinâmicas socioculturais.

\section{REFERÊNCIAS}

ALMEIDA, Alfredo Wagner Berno de. Os quilombos e as novas etnias. In: O`DWYER, Eliane Cantarino (org). Quilombos: identidade étnica e territorialidade. Rio de Janeiro: Editora FGV, 2002.

ARAÚJO, Luis Ernani Bonesso de. O acesso à terra no Estado Democrático de Direito. Tese (Doutorado em Direito) Florianópolis: Programa de Pós-Graduação em Direito da Universidade Federal de Santa Catarina, 1998.

\footnotetext{
11 A posição mais conservadora sobre o conceito dos das comunidades quilombolas está em sintonia com a definição dada pelo Rei de Portugal em resposta a questionamento do Conselho Ultramarino, de 1740, como "toda habitação de negros fugidos que passem de cinco, em parte despovoada, ainda que não tenham ranchos levantados nem se achem pilões neles" (MOURA, 1987). Esses conceitos, segundo Silva, representam "a visão histórico-tradicional" (SILVA, 2003), sustentando que quilombo seria um esconderijo de escravos fugidos, trazendo para o contexto atual, conceitos aplicados há mais de dois séculos.
} 
BARTH, Fredrik. Grupos Étnicos e suas fronteiras. São Paulo: UNESP, 2000.

BRASIL, República Federativa do. Constituição Federal da República de 1988. Disponível em: <http://www.planalto.gov.br/ccivil_03/constituicao/constituicaocompilado.htm>. Acesso em 20.jun.2016.

CHAGAS, Miriam de Fátima. Estudos Antropológicos nas comunidades remanescentes de quilombos: sinais que amplificam a luta por uma vida histórica, vida jurídica. In: LEITE, Ilka Boaventura (org.). Laudos Periciais Antropológicos em debate. Florianópolis: NUER; Brasília: ABA, 2005.

FACHIN, Luiz Edson. Teoria crítica do direito civil. Rio de Janeiro: Renovar, 2003.

FARIA, José Eduardo. Direito e Justiça no século XXI: a crise da Justiça no Brasil. Seminário Direito e Justiça no século XXI, Centro de Estudos Sociais da Universidade de Coimbra, 2003.

FARIA, José Eduardo. Direito e Justiça: a função social do judiciário. São Paulo: Editora Ática, 1989.

FRASER, Nancy. Redistribuição, Reconhecimento e Participação: Por uma concepção integrada de justiça. In SARMENTO, Daniel; IKAWA, Daniel; PIOVESAN, Flávia. (coordenadores). Igualdade, Diferença e Direitos Humanos. Rio de Janeiro: Lúmen Júris, 2008 .

HONNETH, Axel. Luta por reconhecimento: a gramática moral dos conflitos sociais. 2 ed. São Paulo: Ed. 34, 2009.

LEITE, Ilka Boaventura (org.). Laudos Periciais Antropológicos em debate. Florianópolis: NUER; Brasília: ABA, 2005.

LEMES, J. V. M. Territorialidades quilombolas e acesso à justiça: do reconhecimento dos direitos à postura do judiciário brasileiro. Dissertação (Mestrado). Goiânia, Programa de Pósgraduação em Direito Agrário da UFG, 2014.

MARÉS, Carlos Frederico. Multiculturalismo e direitos coletivos. In: SANTOS, Boaventura de Sousa. Reconhecer para Libertar. Os caminhos do cosmopolitismo multicultural. Rio de Janeiro: Civilização Brasileira, 2010.

Antropologia ou Direito? Crítica à autossuficiência do direito. In: Hiléia: Revista de Direito Ambiental da Amazônia. Ano 7-9, n. 13-14. Manaus: Edições Governo do Estado do Amazonas / Secretaria de Estado da Cultura / Universidade do Estado do Amazonas, 2010b.

OLIVEIRA, Ariovaldo Umbelino de. A Geografia das Lutas no Campo. São Paulo: Contexto, 1994.

OLIVEIRA, Oswaldo Martins de. O trabalho e papel do antropólogo nos processos de identificação étnica e territorial. In: LEITE, Ilka Boaventura (org.). Laudos Periciais 
Antropológicos em debate. Florianópolis: NUER; Brasília: ABA, 2005

OLIVEIRA, Roberto Cardoso de. Um conceito antropológico de identidade. In: Identidade, etnia e estrutura social. São Paulo: Pioneira, 1976.

PEREIRA, Débora Duprat de Macedo Brito. O Direito sob o marco da plurietnicidade/multiculturalidade. (2009). Disponível em:

<http://ccr6.pgr.mpf.gov.br/documentos-e-publicacoes/artigos/documentos-epublicacoes/docs_artigos/o_direito_sob_o_marco_da_plurietnicidade_multiculturalidade.pdf> . Acesso em 24/09/2011.

RICOEUR, Paul. Percurso do reconhecimento. São Paulo: Loyola, 2006.

SANTOS, Boaventura de Sousa. Crítica da Razão Indolente: Contra o desperdício da experiência. 7a. ed. São Paulo: Cortez, 2009.

Renovar a teoria crítica e reinventar a emancipação social. Tradução de Mouzar Benedito. São Paulo: Boitempo editorial, 2007.

SANTOS, Milton. Por uma outra globalização: do pensamento único à consciência universal. Rio de Janeiro: Record, 2000.

SAQUET, Marcos Aurélio. Por uma abordagem territorial. In: SAQUET, Marcos Aurélio; SPOSITO, Eliseu Savério (org.) Territórios e territorialidades: teorias, processos e conflitos. São Paulo: Expressão Popular e Programa de Pós-Graduação em Geografia - UNESP, 2009.

SARMENTO, Daniel. Territórios Quilombolas e Constituição: A ADI 3.239 e a Constitucionalidade do Decreto 4.887/03. Parecer emitido nos autos a ADI 3239/04. 2008.

SUNDFELD, Carlos Ari (org.). Comunidades Quilombolas: direito à terra. Brasília: Fundação Cultural Palmares, Ministério da Cultura, Editorial Abaré, 2002.

VIANNA, Luiz Werneck. Corpo e alma da magistratura brasileira. 3. ed. Rio de Janeiro: Revan, 1997

WEBER, Max. Relações comunitárias étnicas. In: Economia e sociedade: fundamentos da sociologia compreensiva. Brasília: Ed. UnB, 2000. 